\title{
Exploration of an Agentic Construct That Impacts Health Behaviors in General Population
}

\author{
José L. Pais-Ribeiro \\ College of Psychology, Porto University, Porto, Portugal \\ Email: jlpr@fpce.up.pt
}

Received June $16^{\text {th }}, 2012$; revised July $15^{\text {th }}, 2012$; accepted August $12^{\text {th }}, 2012$

\begin{abstract}
Hope is defined as the perceived capability to derive pathways to desired goals. The aims of the present study are to discuss hope as a self-regulation construct. Method: The study includes a convenience sample of 615 individuals from the community, $51.1 \%$ females. They fill a questionnaire that includes demographic information, disease behavior, health satisfaction, quality of life, and the Hope Scale. Results: Results suggest a statistically significant relation between hope and outcomes of good health. Conclusions: We can conclude that hope, especially agency thinking, can be an interesting variable to be considered in studies about subjective aspects of health.
\end{abstract}

Keywords: Hope; Health Education; Self Regulation; Health Outcomes

\section{Introduction}

Health was defined at the constitution of the World Health Organization (WHO), in 1948, as being a state of complete physical, mental, and social well-being and not merely the absence of disease or infirmity. Health is something the person has, instead of the absence of disease, contrary to the traditional health assessment procedures measuring symptoms and indicators of disease.

In 1986 the World Health Organization organize de First International Conference on Health Promotion in Ottawa, Canada, creating the Ottawa Charter for Health Promotion. Here they define health promotion as "the process of enabling people to increase control over, and to improve, their health". The key of this process is the control of the route to improve health. It is recognized that individuals should play an important role in maintaining their own health, and that greater attention should be paid to strategies of promoting health (Resnik, 2007). The quality of health is heavily influenced by lifestyle habits. Health habits are not changed by an act of will, but require the exercise of motivational and self regulatory skills.

Researchers have attempted to classify and explain the multitude of factors which can, and do, influence human behavior. Some models/theories tended to dominate the health education field in the past 20 - 30 years, like Health Belief Model (Rosenstock, 1974), Theory of Reasoned Action (Fishbein \& Ajzen, 1975), Social Learning Theory or Social Cognitive Theory (Bandura, 1982; Rotter, 1945), Stages of Change (Bunton, Baldwin, Flynn, \& Whitelaw, 2000), between others.

One of the models that can be useful to change behavior in a new perspective is the Self Regulation Model. This model includes self-monitoring of health related behavior, more the social and cognitive conditions necessary to engage in it, the definition and adoption of goals, and self-motivating incentives and appropriate social support (Bandura, 2005a).

Hope is one construct that deals with dimensions of self regulation (Little et al., 2006), reason why we will focus on this variable to explore its appropriateness for health promotion interventions.

In health assessment, patient-centered measures are more broadly defined and capture health status as perceived by the individual, and should be part of a continuous quality improvement cycle (Barr, 1995). Following the WHO health definition, health status assessment should include physical, emotional and social domains.

During the last 40 years researchers are looking for good measures (Belloc et al., 1971; Bergner, 1985; Patrick et al., 1973), and continue nowadays (Breslow, 2006).

In general, measures of health perception focus on functioning, explains Bandura (2005a). Because health is something the persons have, personal initiative contributes to health. Positive expectancies seem to be associated with better health, and current health is associated with higher subjective life expectancy (Ross \& Mirowsky, 2002).

Models of self-management seem to be important tools for personal initiative. Self-management models develop the motivational and self-regulatory skills which are rooted in an agentic model of health promotion, promotes effective self-management of health, keeping people healthy through their life course (Bandura, 2005b).

Self-regulation, means systematic efforts to direct thoughts, feelings, and actions, toward the attainment of one's goals (de Ridder \& de Wit, 2006; Maes \& Karoly, 2005; Rasmussen et al., 2006; Zimmerman, 2000; Ziegelmann et al., 2006). Selfregulation involves a dynamic motivational system of setting goals, developing and enacting strategies to achieve those goals, appraising progress, revising goals and strategies accordingly, and with the organization of emotional responses, which are intricately linked with cognitive processes (de Ridder \& de Wit, 2006).

Hope construct is an important tool in self-regulation (Little et al., 2006). It is defined as the perceived capability to derive Pathways to desired goals, and motivate oneself via Agency thinking to use those pathways (Snyder, 2002). Snyder has been 
developing the construct and the way to measure it since the mid-1980s. The hope construct includes agency thoughts that "tapes the perceived capacity to initiate (causal capacity) and sustain (agentic capacity and action-control beliefs) movement toward desired goals" (Little et al., 2006: p. 72). High hope individuals are "more likely to ascribe positive and affirming internal pathways messages" to produce routes to those rotes. Researchers agree that Hope seems to be an inherently futureoriented concept (Aspinwall \& Leaf, 2002). In the model of Motivational Systems Theory, personal agency beliefs are the most powerful pattern (Ford, 1992). Cockerham (2005) considers agency as a process in which individuals, influenced by their past but also oriented toward the future, and the present critically evaluate and choose their course of action.

In the field of primary prevention, Snyder (2002) postulated that higher hope people may use information about physical illness as a pathway for prevention efforts. He report empirical studies in which high-hope women reported having stronger intentions to engage in cancer prevention activities, or the highhope persons relative to the low-hope persons reported engageing in more preventative behaviors, or higher hope gay men were less likely to engage in high-risk sexual behaviors. In secondary prevention also reported studies that have found that higher hope is related to better adjustment in coping with severe arthritis, with major burn injuries, with spinal cord injuries, with fibromyalgia, with blindness, in the recovery after an extremely severe automobile accident, and in the adjustment to breast cancer, and health perception. The studies report that hopeful thought facilitate the improvement of strategies for coping with the pain and the motivation to initiate and continue the use of these strategies in patients with chronic pain; it seems that high-hope persons adhere better to medical regimen. Other researchers found that cancer patients with higher levels of hope coped with the disease more effectively (Chi, 2007), that high hope was associated with low risk for depression and a more adaptive coping style, in people coping with spinal cord injuries (Elliott et al. 1991), that hope correlated positively with several measures of psychological adjustment, including optimism, control perceptions, problem-solving, positive affect, and self-esteem (Snyder et al., 1991). Others show that high hope appears to be a potentially key cognitive-motivational construct in the development of adolescents and youths, and that hope reflects a psychological strength that can buffer against the consequences of acute negative life events (Valle et al., 2006).

In the late-20th century, social scientists have turned their attentions to Hope. Researchers in this regard, have located at least 26 theories or definitions, and a handful of validated measures (Lopez et al., 2003). In the present study we assume Snyder (2002) hope definition "as the perceived capability to derive pathways to desired goals, and motivate oneself via agency thinking to use those pathways" (p. 249).

The objective of the present study is to discuss the appropriateness of the use of hope construct as a self regulation variable, to identify the contribution of the hope construct for health outcomes, and inspect the relation between hope, and its two dimensions, and health satisfaction, quality of life perception and disease behavior in a community non patient sample. Our hypothesis is that hope will be positively associated with health outcomes.

\section{Method}

\section{Participants}

A convenience sample with people from the community, includes 615 individuals, $51.1 \%$ females, mean age 39.18 (between 17 and 80 years), 9.1 years of school (between 0 and 23), $19.3 \%$ single, $68.9 \%$ married, $9.6 \%$ divorced and $2.1 \%$ widow, $19.2 \%$ reporting having a disease (no mental disease).

\section{Material}

Hope-Snyder et al. (1991) developed the adult Trait Hope Scale to measure the construct. The scale includes 12 items and consists of four Agency, four Pathways, and four distracter items. Their responses on a 4-point Likert type scale ranging from 1 (definitely false) to 4 (definitely true). In completing the items, respondents are asked to imagine themselves across time and situational contexts. The Portuguese version of the Hope Scale shows similar internal reliability with the original version (Cronbach Alpha of 0.79 for the overall scale -0.74 to 0.88 for the original English version; 0.69 for Pathways - 0.63 to 0.86 for the original version; and 0.73 for Agency- 0.70 to 0.84 for the original version. Researchers agree that the Hope items seem to tap beliefs about self-regulatory competence (Aspinwall \& Leaf, 2002).

Global self-ratings of satisfaction with health-measured with one item, asking about "satisfaction with health", answer in a likert scale type with five positions between "very satisfied" and "very unsatisfied": Higher scores means better satisfaction with health. A review show that one item is an adequate measure of health perception, and research shows that it is an independent predictor of mortality in nearly all of the studies, despite the inclusion of numerous specific health status indicators and other relevant covariates known to predict mortality (Idler \& Benyamini, 1997).

Global quality of life - accessed with one item, asking "how do you classify your quality of life?", answer in a likert scale type with five positions between "very good" and "very bad": Higher scores means better quality of life perception.

Disease behavior - defined as any action implemented by a person feeling sick to clarify his condition and the treatment to follow (Kasl \& Cobb, 1966). In the present study we assess disease behavior with four items asking the number of days, during the last year: "where sick"; "stay at home because a disease"; "stay in bed because a disease"; and "number of visits the doctor". The disease behavior score result from the crude summation of the items (Cronbach Alpha $=0.82$ ).

Existence of a disease - one question asking if they consider that they have a disease in that moment, the name of the disease, and the name of medication taken if any.

Demographic questionnaire - asking about gender, age, education, and marital status.

\section{Procedures}

Participants fill all the questionnaires by themselves, after receiving information about the research, and being asked for their voluntary, confidential, and anonymous participation. After completion, they seal the questionnaire inside an envelope and drop it into a ballot box near a previously defined place (near their work or residence), or mail it to the research team: the correct return rate is $93.34 \%$. Answer all the ques- 
tions takes about 10 minutes.

To the descriptive and inferential statistically analysis we use the Statistical package for Social Sciences V. 15, and for effect size the G*Power 3 (Faul et al., 2007). We inspect differences between groups based on demographics and disease characteristics, more the correlations (with post hoc power confirmation analysis) for the relationship between the focus variable (Hope) and the secondary variables.

\section{Results}

\section{Demographics}

No statistically significant differences where found for Hope and it subscales (pathways and agency), quality of life and satisfaction with health, between genders. For disease behavior females show higher scores of disease behavior, $\mathrm{M}=21.76$, than males, $\mathrm{M}=10.77, \mathrm{t}(613)=2.23, p<.03$. For Hope scale and subscales we found differences between married and not married people for Hope subscale agency $\mathrm{t}(613)=3.41, p$ $<.001$, with married with statistically significant better scores $\mathrm{M}=23.77$, than not married $\mathrm{M}=22.47$. For satisfaction with health we found differences between married and not married, $\mathrm{t}(613)=1.90, p=.05$, with not married people expressing more satisfaction with health $\mathrm{M}=3.88$, than married $\mathrm{M}=3.75$. For people reporting having a disease $(19.2 \%$, report having a disease), we found statistically significant differences for Hope scale $t(612)=2.70, p<.008$, with the one reporting not have a disease with higher Hope $\mathrm{M}=46.93$ than the ones reporting having a disease $\mathrm{M}=44.75$; for the Hope subscale agency the ones reporting without disease express higher Hope $\mathrm{M}=23.67$ than the ones reporting having a disease $\mathrm{M}=22.05, \mathrm{t}(612)=$ $3.65, p<.0001$. The pathways subscale does not have statistically significant differences, suggesting that the Hope differences are based on agency subscale. For health satisfaction we found statistically significant differences with the ones reporting having a disease with lower health perception $\mathrm{M}=3.11$ than the ones do not report having disease $\mathrm{M}=3.95$, $\mathrm{t}(612)=$ $11.85, p<.0001$; for quality of life the same pattern with the ones reporting having a disease with lower quality of life $\mathrm{M}=$ 3.22 than the ones do not report having disease $\mathrm{M}=3.58, \mathrm{t}(612)$ $=5.53, p<.0001$.

\section{Relation between Variables}

Results show that total Hope Scale and it dimensions Pathways and Agency is not correlated with age or education. Hope Scale shows a low correlation with quality of life perception $(\mathrm{r}(615)=.16, p<.0001)$, and with health satisfaction $(\mathrm{r}(615)=.22, p<.0001)$, and no statistically significant correlation with disease behavior: Agency shows a low correlation with quality of life perception $(\mathrm{r}(615)=.22, p<.0001)$, a moderate correlation with health satisfaction $(\mathrm{r}(615)=.30, p<.0001)$, and no statistically significant correlation with disease behavior; Pathways show a low correlation with quality of life $(\mathrm{r}(615)=.09$, $p<.02$ ), and no statistically significant correlation with health satisfaction and disease behavior.

A post hoc power analysis, taken the conventional $\alpha$ error probability $\alpha=.01$, and considered that a rule of thumb and generally accepted arbitrary statistical power value is .80 , for the present sample size $(n=615)$ and the correlation of $r=.22$, between Agency and quality of life perception, the power is .99, and between Agency and health satisfaction for a sample size (n
$=615)$ of $r=.30$, the power is .99 , suggesting a large correlation effect size.

Magaletta and Oliver (1999), found a similar pattern for Hope and its dimensions in a research where the authors related optimism, self efficacy and Hope with general well being. They fond that the will component of Hope (Agency) seems to be the best predictor of well being measured with Wheeler questionnaire (Wheeler, 1991), like in the present study.

\section{Discussion}

The results found with the Hope scale in the study of its relationship with health, quality of life, and disease variables suggest that it can be a promising variable to be studied in relation with these fields. Hope variable is an emergent variable, more than a latent variable (Ozer \& Reise, 1994), and in the first sense seems to be a useful variable to be included in programs with healthy persons in the field of health promotion and primary prevention and with people with chronic diseases or other conditions, to facilitate the adjustment to their disease or condition, including to optimize adherence to treatment processes. It seems that the Hope construct with the two dimensions can make a link with the Self-Regulation Model as Little et al. (2006) defends.

Because human behavior seems to be self-regulated, and the goal-directed actions are self-initiated and purposive activities it seems important to teach people the skills they will need to exert greater control over their lives: it includes problem-solving, goal-setting, and decision-making skills (Little et al., 2006).

From the results, the motivational dimension of Hope, agency thinking, seems to be an interesting variable to be considered in studies about subjective aspects of health behavior.

As a limitation, the most important is the one item questionnaire used to assess health perception, and global quality of life. However, one item measure is always a useful tool in the health setting because it facilitates questioning people, and it is proved that global self-rated health is an independent predictor of mortality (Idler \& Benyamini, 1997). It seems that self-rated health can express different internal conditions that only the person it self can feel, explains Idler and Benyamini (1997). The expression of the magnitude of statistics, as identified by power analysis, as the probability of rejecting the null hypotheses, shows that the significance of the association between agency and the outcome variables "Global self-ratings of satisfaction with health" and "Global quality of life" is enough to consider that agency thinking, in the model of Hope, deserves to be considered when we design programs to implement an healthy life style.

\section{REFERENCES}

Aspinwall, L., \& Leaf, S. (2002). In search of the unique aspects of hope: Pinning our hopes on positive emotions, future-oriented thinking, hard times, and other people. Psychological Inquiry, 13, 276321 .

Bandura, A. (1982). Self-efficacy mechanism in human agency. The American Psychologist, 37, 122-147. doi:10.1037/0003-066X.37.2.122

Bandura, A. (2005a). The primacy of self-regulation in health promotion. Applied Psychology, 54, 245-254. doi:10.1111/j.1464-0597.2005.00208.x

Bandura, A. (2005b). The growing centrality of self-regulation in health promotion and disease prevention. European Journal of Health Psychology, 1, 11-12. 


\section{J. L. PAIS-RIBEIRO}

Barr, J. T. (1995). The outcomes movement and health status measures. Journal of Allied Health, 2, 13-28.

Belloc, N., Breslow, L., \& Hochstim, J. (1971). Measurement of physical health in a general population survey. American Journal of Epidemiology, 93, 328-636.

Bergner, M. (1985). Measurement of health status. Medical Care, 23, 696-704. doi:10.1097/00005650-198505000-00028

Breslow, L. (2006). Health measurement in the third era of health. American Journal of Public Health, 96, 17-19. doi:10.2105/AJPH.2004.055970

Bunton, R., Baldwin, S., Flynn, D., \& Whitelaw, S. (2000). The "stages of change" model in health promotion: Science or ideology. Critical Public Health, 10, 55-70. doi:10.1080/713658223

Chi, G. (2007). The role of hope in patients with cancer. Oncology Nursing Forum, 34, 415-424. doi:10.1188/07.ONF.415-424

Cockerham, W. (2005). Health lifestyle theory and the convergence of agency and structure. Joumal of Health and Social Behavior, 46, 5167. doi: $10.1177 / 002214650504600105$

De Ridder, D., \& de Wit, J. (2006). Self-regulation in health behavior: Concepts, theories, and central issues. In D. de Ridder, \& J. de Wit, (Eds.), Self-regulation in health behavior (pp. 1-23). Chichester: John Wiley \& Sons Ltd.

Elliott, T., Witty, T., Herrick, S., \& Hoffman, J. T. (1991). Negotiating reality after physical loss: Hope, depression, and disability. Journal of Personality and Social Psychology, 61, 608-613. doi:10.1037/0022-3514.61.4.608

Faul, F., Erdfelder, E., Lang, A. G., \& Buchner, A. (2007). G*Power 3: A flexible statistical power analysis program for the social, behavioral, and biomedical sciences. Behavior Research Methods, 39, 175191. doi:10.3758/BF03193146

Fishbein, M., \& Ajzen, I. (1975). Belief, attitude, intention, and behavior: An introduction to theory and research. Reading, MA: Addison-Wesley.

Ford, M. E. (1992). Motivating humans. Goals, emotions, and personal agency beliefs. Newbury Park, CA: SAGE Publications, Inc.

Idler, E., \& Benyamini, Y. (1997). Self rated health and mortality: A review of twenty-seven community studies. Journal of Health and Social Behavior, 38, 21-37. doi:10.2307/2955359

Kasl, S. V., \& Cobb, S. (1966). Health behavior, illness behavior and sick role behavior. Archives of Environmental Health, 12, 246-266.

Little, T., Snyder, C., \& Wehmeyer, M. (2006). The agentic self: On the nature and origins of personal agency across life span. In D. Mroczek, \& T. Little (Eds.), Handbook of personality development (pp. 61-79). New Jersey: Lawrence Erlbaum Associates, Publishers.

Lopez, S., Snyder, C., \& Pedrotti, J. (2003). Hope: Many definitions, many measures. In S. Lopez, \& C. Snyder (Eds.), Positive psychological assessment: A handbook of models and measures (pp. 91106). Washington DC: American Psychological Association. doi:10.1037/10612-006

Maes, S., \& Karoly, P. (2005). Self-regulation assessment and intervention in physical health and illness: A review. Applied Psychology, 54, 267-299. doi:10.1111/j.1464-0597.2005.00210.x

Magaletta, P., \& Oliver, J. (1999). The hope construct, will, and ways: Their relations with self-efficacy, optimism, and general well-being. Journal of Clinical Psychology, 55, 539-551. doi:10.1002/(SICI)1097-4679(199905)55:5<539::AID-JCLP2>3.0.C $\underline{\mathrm{O} ; 2-\mathrm{G}}$

Ozer, D., \& Reise, S. (1994). Personality assessment. Annual Review of Psychology, 45, 357-388. doi:10.1146/annurev.ps.45.020194.002041

Patrick, D., Bush, J., \& Chen, M. (1973). Methods for measuring levels of well-being for a health status index. Health Services Research, 8, 228-245.

Rasmussen, H., Wrosch, C., Scheier, M., \& Carver, C. (2006). Selfregulation processes and health: The importance of optimism and goal adjustment. Journal of Personality, 74, 1721-1747. doi:10.1111/j.1467-6494.2006.00426.x

Resnik, D. (2007). Responsibility for health: Personal, social, and environmental. Journal of Medical Ethics, 33, 444-445. doi:10.1136/jme.2006.017574

Rosenstock, I. M. (1974). The health belief model and preventive health behavior. Health Education Monographs, 2, 354-386.

Ross, C. E., \& Mirowsky, J. (2002). Family relationships, social support and subjective life expectancy. Journal of Health and Social Behavior, 43, 469-489. doi:10.2307/3090238

Rotter, J. B. (1945). Social learning and clinical psychology. Englewood-Cliffs, NJ: Prentice-Hall.

Snyder, C. R. (2002). Hope theory: Rainbows in the mind. Psychological Inquiry, 13, 249-275. doi:10.1207/S15327965PLI1304 01

Snyder, C. R., Harris, C., Anderson, J. R., Holleran, S. A., Irving, L. M., Sigmon, S. T., Harney, P. et al. (1991). The will and the ways: Development and validation of an individual difference measure of hope. Journal of Personality and Social Psychology, 60, 570-585. doi:10.1037/0022-3514.60.4.570

Valle, M., Huebner, E., \& Suldo, S. (2006). An analysis of hope as a psychological strength. Journal of School Psychology, 44, 393-406. doi: $10.1016 /$ j.jsp.2006.03.005

Wheeler, R. J. (1991). The theoretical and empirical structure of general well-being. Social Indicators Research, 24, 71-79. doi:10.1007/BF00292651

Ziegelmann, J., Lippke, S., \& Schwarzer, R. (2006). Subjective residual life expectancy in health self-regulation. Journal of Gerontology, $61 B, 195-201$.

Zimmerman, J. (2000). Attaining self-regulation: A social cognitive perspective. In M. Boekaerts, P. Pintrich, \& M. Zeidner (Eds.), Handbook of self-regulation (pp. 13-39). San Diego, CA: Academic Press. doi:10.1016/B978-012109890-2/50031-7 